\title{
Bisphosphonate-Functionalized Gold Nanoparticles for Contrast-Enhanced X-Ray Detection of Breast Microcalcifications
}

\author{
Lisa E. Cole ${ }^{1,3}$, Tracy Vargo-Gogola ${ }^{2,3}$, and Ryan K. Roeder ${ }^{1,3}$ \\ ${ }^{1}$ Department of Aerospace and Mechanical Engineering, Bioengineering Graduate Program, \\ University of Notre Dame, Notre Dame, IN 46556, USA \\ 2Department of Biochemistry and Molecular Biology, Indiana University Simon Cancer Center, \\ Indiana University School of Medicine - South Bend, South Bend, IN 46617, USA \\ ${ }^{3}$ Harper Cancer Research Institute, University of Notre Dame, Notre Dame, IN 46556, USA
}

\section{Abstract}

Microcalcifications are one of the most common abnormalities detected by mammography for the diagnosis of breast cancer. However, the detection of microcalcifications and correct diagnosis of breast cancer are limited by the sensitivity and specificity of mammography. Therefore, the objective of this study was to investigate the potential of bisphosphonate-functionalized gold nanoparticles (BP-Au NPs) for contrast-enhanced radiographic detection of breast microcalcifications using two models of breast microcalcifications which allowed for precise control over levels of hydroxyapatite (HA) mineral within a low attenuating matrix. First, an in vitro imaging phantom was prepared with varying concentrations of HA uniformly dispersed in an agarose hydrogel. The X-ray attenuation of HA-agarose compositions labeled by BP-Au NPs was increased by up to $26 \mathrm{HU}$ compared to unlabeled compositions for HA concentrations ranging from 1-10 $\mathrm{mg} / \mathrm{mL}$. Second, an ex vivo tissue model was developed to more closely mimic the heterogeneity of breast tissue by injecting varying concentrations of HA in a Matrigel carrier into murine mammary glands. The X-ray attenuation of HA-Matrigel compositions labeled by BP-Au NPs was increased by up to $289 \mathrm{HU}$ compared to unlabeled compositions for HA concentrations ranging from $0.5-25 \mathrm{mg} / \mathrm{mL}$, which included an HA concentration $(0.5 \mathrm{mg} / \mathrm{mL})$ that was otherwise undetectable by micro-computed tomography. Cumulatively, both models demonstrated the ability of BP-Au NPs to enhance contrast for radiographic detection of microcalcifications, including at a clinically-relevant imaging resolution. Therefore, BP-Au NPs may have potential to improve clinical detection of breast microcalcifications by mammography.

\section{Keywords}

bisphosphonate; breast cancer; computed tomography; contrast agent; gold nanoparticles; mammary gland; microcalcification; X-ray imaging

(C) 2013 Elsevier Ltd. All rights reserved.

Correspondence: Ryan K. Roeder, Ph.D., Associate Professor, Department of Aerospace and Mechanical Engineering, Bioengineering Graduate Program, 148 Multidisciplinary Research Building, University of Notre Dame, Notre Dame, IN 46556, Phone: (574) 631-7003, rroeder@nd.edu.

Publisher's Disclaimer: This is a PDF file of an unedited manuscript that has been accepted for publication. As a service to our customers we are providing this early version of the manuscript. The manuscript will undergo copyediting, typesetting, and review of the resulting proof before it is published in its final citable form. Please note that during the production process errors may be discovered which could affect the content, and all legal disclaimers that apply to the journal pertain. 


\section{Introduction}

Breast cancer is the most common cancer and second leading cause of cancer-related deaths among women in the United States [1]. Early detection by mammography is the current clinical gold standard in breast cancer screening and is considered to be the best hope for controlling the disease due to a demonstrated decrease in breast cancer mortality $[2,3]$. Microcalcifications are one of the most common abnormalities detected by mammography [4,5] and are coincident with 30-50\% of breast cancers detected by mammograms [6-8]. Microcalcifications are deposits of hydroxyapatite (HA) or calcium oxalate $(\mathrm{CaOx})$ mineral within the breast tissue [9-12], which exhibit high X-ray attenuation relative to the low attenuating breast tissue facilitating detection by mammography.

The detection of microcalcifications and correct diagnosis of breast cancer are limited by the sensitivity and specificity of mammography. Mammographically-detected microcalcifications range in size from $0.1-1.0 \mathrm{~mm}$, but smaller microcalcifications are detected histologically [6]. Limitations in sensitivity can result in the missed detection of cancerous lesions at an early stage, or false negatives, and therefore lost opportunity for early treatment [13]. Studies have reported that $10-30 \%$ of all breast lesions are missed during routine mammographic screening $[6,14]$. Limitations in specificity can result in false positives [15] and unnecessary biopsies, which increase patient anxiety and healthcare costs [16]. The detection of microcalcifications is limited by their small size and the presence of other structures in the breast, such as fibrous tissue, ducts and blood vessels, which may be mistaken for microcalcifications due to exhibiting greater X-ray attenuation than surrounding tissue [6]. Therefore, improvements are needed for detecting microcalcifications during mammographic screening for breast cancer.

X-ray contrast agents [17] could be used to improve the sensitivity and specificity of detecting breast microcalcifications by mammography. Improved sensitivity could be achieved by providing enhanced X-ray contrast for small microcalcifications that are otherwise below the detection limit of mammography, thus enabling earlier detection. Improved specificity could be achieved using a targeted X-ray contrast agent.

Gold nanoparticles (Au NPs) have received recent attention as a potential X-ray contrast agent due to exhibiting greater X-ray attenuation and improved vascular retention compared to iodinated molecular agents [18-20]. Additionally, Au NPs are widely reported to be noncytotoxic, readily synthesized, and readily surface functionalized for colloidal stability and targeted delivery [21]. Au NPs surface functionalized with ligands such as antibodies [2225], peptides [26] or other tumor-specific biomarkers [27] have demonstrated potential as an actively targeted X-ray contrast agent for cancer cells in vitro or tumors in vivo.

Bisphosphonate-functionalized Au NPs (BP-Au NPs) were recently investigated as a targeted X-ray contrast agent for microdamage in bone tissue [28,29]. Bisphosphonates, such as alendronate, are used as a pharmaceutical in the treatment of osteoporosis [30] due to exhibiting a high binding affinity for HA, the mineral component of bone [31]. BP-Au NPs exhibited colloidal stability in physiological media, a high binding affinity for HA crystals in vitro, and targeted labeling of damaged bone tissue in vitro [28,29]. Interestingly, $\mathrm{HA}$ is also the mineral component of the type of breast microcalcifications known to be associated with malignant lesions [9-12,32].

Therefore, the objective of this study was to investigate the potential of BP-Au NPs for contrast-enhanced radiographic detection of breast microcalcifications. Two models of breast microcalcifications were developed for precisely controlling levels of HA mineral within a low attenuating matrix. First, an in vitro imaging phantom was prepared with 
varying concentrations of HA uniformly dispersed in an agarose hydrogel. Second, an $e x$ vivo murine tissue model was developed to more closely mimic the heterogeneity of breast tissue, and also lay the groundwork for an in vivo model, by injecting varying concentrations of HA in a Matrigel carrier into the fat pad of the number 4 mouse mammary gland.

\section{Materials and Methods}

\subsection{Synthesis and characterization of BP-Au NPs}

Au NPs were synthesized to a mean particle diameter of $\sim 13 \mathrm{~nm}$ using the citrate reduction method [33], as previously described in detail [28,29]. Briefly, $0.1 \mathrm{~g}$ gold (III) chloride trihydrate $\left(\mathrm{HAuCl}_{4} \cdot 3 \mathrm{H}_{2} \mathrm{O}, 299.9 \%\right.$, Sigma-Aldrich, St. Louis, MO) was added to $500 \mathrm{~mL}$ de-ionized (DI) water and brought to a boil while stirring. Once boiling, $0.5 \mathrm{~g}$ of trisodium citrate dihydrate $\left(\mathrm{Na}_{3} \mathrm{C}_{6} \mathrm{H}_{5} \mathrm{O}_{7} \cdot 2 \mathrm{H}_{2} \mathrm{O}\right.$, ACS reagent, $>99 \%$, Sigma-Aldrich) was added to the gold solution and left to boil, while covered, for $20 \mathrm{~min}$ before removing heat and stirring overnight. The solution volume was adjusted back to $500 \mathrm{~mL}$ after reaching room temperature, resulting in a final solution with a gold concentration of $\sim 0.5 \mathrm{mM}$ and a red wine color.

$\mathrm{Au}$ NPs were prepared for bisphosphonate surface functionalization by mixing $240 \mathrm{~mL}$ of as-synthesized Au NPs with $10 \mathrm{~mL} 2 \mathrm{wt} \%$ polyvinyl alcohol (PVA 10-98, 61,000 Da, Fluka, St. Louis, MO) and $5.8 \mathrm{~g}$ ion exchange resin (Dowex Marathon, MR-3, SigmaAldrich, St. Louis, MO) to remove excess ions. The spent resin was then filtered from the Au NPs (grade 3, Whatman, Piscataway, NJ). Au NPs were surface functionalized with alendronate sodium trihydrate $\left(\mathrm{C}_{4} \mathrm{H}_{12} \mathrm{NaNO}_{7} \mathrm{P}_{2} \cdot 3 \mathrm{H}_{2} \mathrm{O}, \geq 97 \%\right.$, Sigma-Aldrich, St. Louis, $\mathrm{MO}$ ), which provided a primary amine for binding gold opposite a bisphosphonate functional group for targeting calcium in HA. Four $\mathrm{mL}$ of a $0.01 \mathrm{M}$ solution of alendronate was added to $250 \mathrm{~mL}$ of PVA-Au NPs and left to stir overnight. Excess bisphosphonate molecules were removed by dialysis (Spectra/Por, $\mathrm{MWCO}=3500 \mathrm{Da}$, Spectrum Laboratories, Rancho Dominquez, CA) against DI water for $3 \mathrm{~d}$, changing the water at least 3 times daily.

BP-Au NPs have been thoroughly characterized in previous studies, which included measurements of the mean particle diameter, mean hydrodynamic diameter, colloidal stability in physiological media, and bisphosphonate surface density [28,29]. All BP-Au NPs prepared in this study were characterized by dynamic light scattering (DLS, Zetasizer Nano ZS90, Malvern Instruments Ltd., Worcestershire, UK) and ultraviolet-visible (UV-vis) spectroscopy (Nanodrop 200C, Thermo Scientific, Wilmington, DE) to ensure consistency in the mean hydrodynamic diameter and colloidal stability, respectively. The hydrodynamic diameter was measured using DLS after diluting as-prepared BP-Au NPs in DI water to a final gold concentration of $\sim 0.5 \mu \mathrm{M}$ and reported as the mean of three samples. Colloidal stability was verified by measuring the surface plasmon resonance (SPR) peak using UV-vis spectroscopy after diluting as-prepared BP-Au NPs in DI water to a final gold concentration of $0.4 \mathrm{mM}$. Gold concentrations were measured using inductively coupled plasma-optical emission spectroscopy (ICP-OES, Optima 3000, Perkin Elmer, Inc. Waltham, MA) after acidifying with $3 \%$ aqua regia $\left(3 \mathrm{HCl}: 1 \mathrm{HNO}_{3}\right)$. Calibration curves were created by diluting certified standard gold solutions (Assurance Grade, SPEX CertiPrep, Metuchen, NJ).

\subsection{In vitro imaging phantom}

An in vitro imaging phantom of breast microcalcifications was created by mixing varying concentrations of HA crystals in an agarose hydrogel. Whisker-shaped HA crystals, exhibiting a mean length and width of $\sim 18 \mathrm{x} \sim 2 \mu \mathrm{m}$, were synthesized using the chelate decomposition method, as described elsewhere [34]. The specific surface area of the HA 
crystals was $5.63 \mathrm{~m}^{2} / \mathrm{g}$ as measured using Brunauer-Emmett-Teller (BET) $\mathrm{N}_{2}$ adsorption (Autosorb-1, Quantachrome Instruments, Boynton Beach, FL) [28]. HA crystals were added to a $2 \mathrm{wt} \%$ agarose hydrogel (Sigma-Aldrich, St. Louis, MO) at varying HA concentrations of $0,0.5,1.0,2.5,5.0,10$, and $25 \mathrm{mg} / \mathrm{mL}$ and gelled into $10 \mu \mathrm{L}$ pellets at $4^{\circ} \mathrm{C}$. The HA concentration in each pellet was verified by measuring the calcium concentration with ICPOES using the methods described above. Calibration curves were created by diluting certified standard calcium solutions (Assurance Grade, SPEX CertiPrep).

HA-agarose pellets labeled by BP-Au NPs were prepared by labeling HA crystals with BP$\mathrm{Au}$ NPs prior to forming the pellets. HA concentrations of 0.5, 1.0, 2.5, 5.0, 10, and $25 \mathrm{mg} /$ $\mathrm{mL}$ were incubated in DI water containing $40 \mathrm{mg} / \mathrm{L}(0.2 \mathrm{mM})$ BP-Au NPs for $24 \mathrm{~h}$ to allow for maximum binding of the BP-Au NPs to the HA crystals [28]. Thus, each HA concentration was exposed to the same BP-Au NP concentration for the same length of time. Unbound BP-Au NPs were separated from HA crystals by centrifugation at $\sim 700 \mathrm{~g}$ for $2 \mathrm{~min}$. HA crystals labeled by BP-Au NPs were collected using $0.45 \mu \mathrm{m}$ filter paper (Nylaflo, Pall Corporation, Ann Arbor, MI), rinsed with $10 \mathrm{~mL}$ DI water, dried overnight in an oven at $37^{\circ} \mathrm{C}$, and stored under vacuum. Labeled HA crystals were mixed with $2 \mathrm{wt} \%$ agarose solution and gelled into $10 \mu \mathrm{L}$ pellets at $4^{\circ} \mathrm{C}$.

Labeled and unlabeled HA-agarose pellets were imaged in Eppendorf tubes by microcomputed tomography (micro-CT, $\mu \mathrm{CT}-80$, Scanco Medical AG, Brüttisellen, Switzerland) at $45 \mathrm{kVp}, 177 \mu \mathrm{A}, 600 \mathrm{~ms}$ integration time, and $10 \mu \mathrm{m}$ resolution for 250 slices. The standard $0.5 \mathrm{~mm}$ aluminum filter was removed to increase the number of low energy photons to approximate mammographic imaging. The mean ( \pm standard deviation) sampled volume for each pellet was $5.2(1.3) \mathrm{mm}^{3}$. The measured mean linear attenuation coefficient of the HA-agarose pellets was converted to Hounsfield units (HU) using an internal sample calibration for air $(-1000 \mathrm{HU})$ and water $(0 \mathrm{HU})$ controls measured from 10 slices in the same sample tube. The X-ray attenuation measured for each labeled and unlabeled HA concentration was reported in $\mathrm{HU}$ as the mean ( \pm standard deviation) of five samples.

The percent of BP-Au NPs bound to HA crystals was measured as the concentration of unbound BP-Au NPs subtracted from the initial BP-Au NP concentration, divided by the initial BP-Au NP concentration. The initial gold concentration and the concentration of unbound BP-Au NPs were measured using ICP-OES, as described above. The mass of BPAu NPs bound per HA surface area ( $\mathrm{mg} \mathrm{Au} / \mathrm{m}^{2} \mathrm{HA}$ ), or surface density, was calculated using the measured specific surface area of the HA crystals. The mean ( \pm standard deviation) percent of BP-Au NPs bound and mass of BP-Au NPs bound per HA surface area were measured from three samples for each HA concentration. The presence and surface density of BP-Au NPs on HA crystal surfaces were also verified using field emission scanning electron microscopy (FE-SEM, 400 XHR, FEI, Hillsboro, OR). Specimens were prepared by dropping a solution of HA crystals labeled with BP-Au NPs in $90 \%$ ethanol on a heated SEM stub and coating with $2.5 \mathrm{~nm}$ iridium by sputter deposition. Specimens were imaged at an accelerating voltage of $5 \mathrm{kV}$ and current of $6.3 \mathrm{pA}$.

\subsection{Ex vivo tissue model}

Mature mammary glands (MGs) from 8-12 week old nulliparous FVB female mice (Charles River Laboratories International, Inc., Wilmington, MA) were used to develop an ex vivo tissue model of microcalcifications. All studies were approved by the Institutional Animal Care and Use Committee at the University of Notre Dame and were conducted in accordance with the guidelines of the U.S. Public Health Service Policy for Humane Care and Use of Laboratory Animals. All efforts were made to minimize suffering of the mice. Mice were euthanized and dissected to expose the left and right number 4 MGs. HA crystals were mixed with Matrigel (BD Matrigel, BD Sciences, Bedford, MA), a hydrogel comprised 
of extracellular matrix proteins, at HA concentrations of $0,0.5,5.0$, and $25 \mathrm{mg} / \mathrm{mL}$, and HAMatrigel compositions were immediately injected into the fat pad of MGs at a dose of 50 $\mu \mathrm{L}$.

HA-Matrigel compositions labeled with BP-Au NPs were prepared by labeling HA crystals with BP-Au NPs prior to mixing with Matrigel. Three concentrations of HA crystals, 0.5, 5 and $25 \mathrm{mg} / \mathrm{mL}$, were labeled with two different concentrations of BP-Au NPs $(10 \mathrm{mg} / \mathrm{L}$ and $74 \mathrm{mg} / \mathrm{L}$ ) for $24 \mathrm{~h}$ using the same methods described above for the in vitro imaging phantom. After labeling, unbound BP-Au NPs were separated from HA crystals by centrifugation at $\sim 700 \mathrm{~g}$ for $2 \mathrm{~min}$. HA crystals labeled by BP-Au NP were collected using $0.45 \mu \mathrm{m}$ filter paper (Nylaflo), rinsed with $10 \mathrm{~mL}$ DI water, dried overnight in an oven at $37^{\circ} \mathrm{C}$, and stored under vacuum. Labeled HA crystals were mixed with Matrigel and injected into the MGs, as described above.

MGs containing HA-Matrigel compositions were imaged ex vivo by micro-CT within $24 \mathrm{~h}$ after injection. Labeled and unlabeled HA-Matrigel compositions were allowed to set for 1 min, before MGs were dissected and stored in phosphate buffered saline at $4^{\circ} \mathrm{C}$. In order to eliminate movement of the MGs and maintain tissue hydration during micro-CT imaging, MGs were embedded in 2\% agarose and placed in a polyethylene specimen tube (14 mm diameter). MGs were imaged by micro-CT ( $\mu \mathrm{CT}-80$, Scanco Medical AG) at $45 \mathrm{kVp}, 177$ $\mu \mathrm{A}$, and $600 \mathrm{~ms}$ integration time at a high resolution $(10 \mu \mathrm{m})$ and a more clinically-relevant lower resolution $(100 \mu \mathrm{m})$. The standard $0.5 \mathrm{~mm}$ aluminum filter was removed to increase the number of low energy photons to approximate mammographic imaging. The volume of interest (VOI) for analysis was $3.01 \mathrm{~mm}^{3}$ at $10 \mu \mathrm{m}$ resolution or $5.67 \mathrm{~mm}^{3}$ at $100 \mu \mathrm{m}$ resolution for each MG, which included both the HA-Matrigel composition and MG tissue. The measured mean linear attenuation coefficient of the VOI was converted to Hounsfield units (HU) using an internal calibration for air $(-1000 \mathrm{HU})$ and water $(0 \mathrm{HU})$ controls that were included in the first and last micro-CT scan performed each day. The X-ray attenuation measured for each labeled and unlabeled HA concentration was reported in HU as the mean ( \pm standard deviation) of five samples.

The percent of BP-Au NPs bound to HA crystals and the mass of BP-Au NPs bound per HA surface area $\left(\mathrm{mg} \mathrm{Au} / \mathrm{m}^{2} \mathrm{HA}\right)$ were determined from the initial gold concentration and concentration of the unbound BP-Au NPs measured by ICP-OES, as described above. The mean ( \pm standard deviation) percent of BP-Au NPs bound and mean mass of BP-Au NPs bound per HA surface area were measured from three samples for each HA concentration.

\subsection{Statistical Methods}

The accuracy and precision of the in vitro imaging phantom model was validated by comparing the expected HA concentration within $10 \mu \mathrm{L}$ HA-agarose pellets with the measured HA concentration from ICP-OES using a paired $t$-test and linear least squares regression, respectively (JMP 10.0. SAS Institute, Inc., Cary, NC). For both the in vitro and ex vivo models, $\mathrm{X}$-ray attenuation was correlated with HA concentration using linear least squares regression and differences in the X-ray attenuation of labeled and unlabeled HA concentrations were examined using two-way analysis of variance (ANOVA). Differences in the binding of BP-Au NPs to HA crystals in either model were also examined using oneand two-way ANOVA. Post hoc comparisons were performed using unpaired Student's $t$ tests. The level of significance for all tests was set at $p<0.05$. 


\section{Results and Discussion}

\subsection{Characterization of BP-Au NPs}

BP-Au NPs were synthesized using the citrate reduction method and surface functionalized with alendronate, a bisphosphonate with a primary amine for binding to gold surfaces opposite phosphonate groups for targeting calcium ions on HA crystal surfaces (Fig. 1a). Resulting BP-Au NPs were spherical and monodispersed with a mean ( \pm standard deviation) particle diameter of 12.8 (1.6) nm (Fig. 1b), as measured by TEM [28]. The colloidal stability of BP-Au NPs was characterized using DLS and UV-vis spectroscopy. The mean ( \pm standard deviation) hydrodynamic diameter was 45.8 (1.5) nm, as measured by DLS (Fig. 1c), which was consistent with previously published results for $13 \mathrm{~nm}$ BP-Au NPs [29]. The characteristic SPR peak was observed at $\sim 527 \mathrm{~nm}$ in UV-vis spectroscopy (Fig. 1d), which was also consistent with previously published results for $13 \mathrm{~nm}$ BP-Au NPs [28,29]. The hydrodynamic diameter and characteristic SPR peak were characterized for each batch of BP-Au NPs synthesized and over time to ensure that BP-Au NPs remained well-dispersed and stable.

Colloidal stability is critically important for a targeted nanoparticle contrast agent as nanoparticles must remain dispersed in relevant media for targeted delivery. As-prepared $\mathrm{Au}$ NPs are stable in water, but are typically unstable in physiological media, requiring the addition of appropriate functional ligands [29,35]. BP-Au NPs were previously shown to exhibit colloidal stability in phosphate buffered saline (PBS) and fetal bovine serum (FBS) for at least $7 \mathrm{~d}$ due to a combination of the steric and electrostatic stabilizing effects of bisphosphonate ligands [29].

\subsection{In vitro imaging phantom}

An in vitro imaging phantom was developed to investigate the potential of BP-Au NPs for contrast-enhanced X-ray detection of microcalcifications. Microcalcifications in breast tissue were modeled by mixing varying concentrations of HA crystals in an agarose solution. Agarose provided a matrix with low X-ray attenuation for uniformly dispersing the HA crystals. The range of HA concentrations was used to model different stages of microcalcification burden, including the earliest stages when microcalcifications may be too small to be detected by mammography [6].

The accuracy and precision of the model was validated by correlating the expected HA concentration within HA-agarose pellets against the measured HA concentration from ICPOES (Fig. 2). Measured HA concentrations were less than expected HA concentrations ( $p<$ 0.05 , paired $t$-test), most likely due to losses of HA during mixing and subsequent analysis, but the mean error was only $-8.3 \%$, indicating reasonable accuracy. More importantly, linear least squares regression indicated that HA concentrations were highly reproducible $\left(R^{2}=0.992\right)$. Therefore, the in vitro imaging phantom was determined to exhibit sufficient accuracy and precision for investigating the effects of the HA concentration and BP-Au NP labeling on X-ray attenuation.

The X-ray attenuation of unlabeled and BP-Au NP labeled HA concentrations was measured using micro-CT. X-ray attenuation increased with increasing HA concentration for both unlabeled and labeled HA groups ( $p<0.001$, ANOVA) (Fig. 3). The X-ray attenuation of unlabeled HA exhibited a linear relationship with HA concentration $\left(R^{2}=0.997\right)$, as expected. All unlabeled HA concentrations exhibited significantly greater X-ray attenuation compared to the agarose-only $(0 \mathrm{mg} / \mathrm{mL} \mathrm{HA})$ control $(p<0.005, t$-test). Labeling by BP-Au NPs enhanced the X-ray attenuation of HA concentrations ranging from $1-10 \mathrm{mg} / \mathrm{mL}$ 
compared to unlabeled HA at the same concentration ( $p<0.005$, $t$-test) (Fig. 3). A maximum differential contrast enhancement of $26 \mathrm{HU}$ was achieved at $5 \mathrm{mg} / \mathrm{mL} \mathrm{HA}$.

The X-ray attenuation of the lowest $(0.5 \mathrm{mg} / \mathrm{mL})$ and highest $(25 \mathrm{mg} / \mathrm{mL}) \mathrm{HA}$ concentrations were not increased when labeled by BP-Au NPs. Therefore, the percent of the BP-Au NP dose bound to HA and the mass of BP-Au NPs bound per HA surface area (mg Au/ $\mathrm{m}^{2} \mathrm{HA}$ ) were measured to investigate differences with HA concentration. Complete binding of the BP-Au NP dose occurred at HA concentrations $\geq 2.5 \mathrm{mg} / \mathrm{mL}$ and the percent binding decreased with decreasing HA concentration ( $p<0.0001$, ANOVA) (Fig. 4a). On the other hand, HA crystals surfaces were saturated with BP-Au NPs at HA concentrations $\leq$ $2.5 \mathrm{mg} / \mathrm{mL}$ and the surface density decreased with increasing HA concentration $(p<0.0001$, ANOVA) (Fig. 4b). The decreased surface density of BP-Au NPs with increasing HA concentration was also directly confirmed by electron microscopy (Fig. 5). Thus, BP-Au NPs were unable to provide enhanced X-ray contrast at $0.5 \mathrm{mg} / \mathrm{mL}$ and $25 \mathrm{mg} / \mathrm{mL}$ due to a limited number of total available binding sites at low HA concentrations and a limited number of BP-Au NPs available for binding at high HA concentrations, respectively.

These results suggest a limit to contrast enhancement at HA concentrations $\leq 0.5 \mathrm{mg} / \mathrm{mL}$ using this model, since HA crystal surfaces were saturated with BP-Au NPs (Fig. 4b). Contrast enhancement at the lowest HA concentration $(0.5 \mathrm{mg} / \mathrm{mL})$ would seem to be advantageous for detecting HA concentrations otherwise virtually undetectable over the background signal. Therefore, contrast enhancement at HA concentrations $\leq 0.5 \mathrm{mg} / \mathrm{mL}$ would require either more sensitive imaging methods or the delivery of a greater mass concentration of Au NPs. On the other hand, a lower limit in HA concentration for contrast enhancement might also be advantageous to prevent false positives. Thus, the level of such a limit or the minimum microcalcification burden for clinical breast cancer diagnosis is critically important but currently unknown.

These results also suggest that contrast enhancement could be achieved at higher HA concentrations (e.g., $25 \mathrm{mg} / \mathrm{mL}$ ) by simply increasing the BP-Au NP dose. However, contrast enhancement is not necessary at high HA concentrations (e.g., $25 \mathrm{mg} / \mathrm{mL}$ ) that are readily detected without contrast enhancement. Moreover, an upper limit in HA concentration for contrast enhancement may be advantageous for determining microcalcification burden. Therefore, an optimal BP-Au NP dose must be determined for providing sufficient contrast enhancement over the most appropriate range of HA concentrations, preferably below the detection limits in the absence of contrast enhancement. For this reason, a higher and lower BP-Au NP concentration was investigated in the ex vivo tissue model described below.

Interestingly, the greatest X-ray contrast enhancement in this model occurred at an HA concentration of $5 \mathrm{mg} / \mathrm{mL}$. Unlabeled $\mathrm{HA}$ at $5 \mathrm{mg} / \mathrm{mL}$ exhibited $\sim 21 \mathrm{HU}$, which is similar to the X-ray attenuation of the glandular tissue component of human breast tissue at $45 \mathrm{kVp}$ [36], and labeling with BP-Au NPs increased the X-ray attenuation to $47 \mathrm{HU}$. This suggests that BP-Au NPs may be particularly useful for providing enhanced contrast to detect microcalcifications in dense breast tissue, which is composed of relatively greater amounts of glandular tissue. This finding is clinically significant because sensitivity for the detection microcalcifications is dramatically reduced in women with radiographically dense breast tissue [37-39], while increased breast density is associated with an increased risk of cancer [40].

The in vitro imaging phantom demonstrated the ability of BP-Au NPs to enhance X-ray contrast for the detection of microcalcifications (Fig. 3), but was not without limitations. The measured X-ray attenuation of agarose was approximately $-14 \mathrm{HU}$ or $1.189 \mathrm{~cm}^{-1}$ at 45 
$\mathrm{kVp}$, which provided a good average approximation, but was higher than adipose tissue $(-260 \mathrm{HU}$ at $45 \mathrm{kVp}$ ) and lower than glandular tissue (20 HU at $45 \mathrm{kVp}$ ) [36]. Additionally, HA crystals were uniformly dispersed within the agarose matrix. However, breast microcalcifications may appear as single crystals or clustered aggregates of many crystals and the degree of clustering may be used to distinguish between malignant and benign lesions [41,42]. Therefore, an ex vivo tissue model was developed to more closely recapitulate the heterogeneity of microcalcifications in breast tissue.

\subsection{Ex vivo murine tissue model}

An ex vivo murine tissue model was developed to more closely mimic the heterogeneity of breast tissue and also lay the groundwork for an in vivo model. Murine MGs are important models for studying human breast cancer [43] and were used in this study to mimic the low $\mathrm{X}$-ray attenuation of adipose tissue in the human breast [36]. Varying concentrations of unlabeled and labeled HA were mixed with Matrigel and injected into the fat pad of excised murine MGs to model the heterogeneity of microcalcifications in breast tissue. Varying HA concentrations were used to model different levels of microcalcification burden, including the earliest stages when microcalcifications may be too small to be detected by mammography [6]. The injection volume and HA concentration were readily tailored providing a straightforward and reproducible model for creating microcalcifications of known HA concentration for investigating X-ray contrast agents. Breast microcalcifications have also been biologically-induced in mice and rats via implanted cancer cells [44] and delivery of exogenous growth factors [45-47], respectively, but these models require separate measurements to quantify the HA concentration or microcalcification burden rather than offering a priori control.

X-ray attenuation increased with increasing HA concentration for both unlabeled and labeled HA-Matrigel compositions imaged by micro-CT at both high $(10 \mu \mathrm{m})$ and low $(100$ $\mu \mathrm{m})$ resolution $(p<0.001$, ANOVA) (Fig. 6$)$. The X-ray attenuation of unlabeled HA exhibited a linear relationship with HA concentration at both high and low imaging resolution $\left(R^{2}>0.993\right)$, as expected. Unlabeled HA concentrations of 5 and $25 \mathrm{mg} / \mathrm{mL}$ exhibited significantly greater X-ray attenuation compared to the Matrigel control $(0 \mathrm{mg} / \mathrm{mL}$ HA) at both high ( $p<0.005, t$-test) and low ( $p<0.05, t$-test) resolution, but differences between $0.5 \mathrm{mg} / \mathrm{mL} \mathrm{HA}$ and the Matrigel control were not statistically significant $(p>0.28)$ (Fig. 6). Therefore, HA-Matrigel compositions containing $0.5 \mathrm{mg} / \mathrm{mL}$ HA were undetectable relative to the Matrigel-only control. Interestingly, the microcalcifications created at $0.5 \mathrm{mg}$ / $\mathrm{mL}$ HA appeared to be less than $0.1 \mathrm{~mm}$ in size in micro-CT images, and increased in size with HA concentration to greater than $1.0 \mathrm{~mm}$ at $25 \mathrm{mg} / \mathrm{mL} \mathrm{HA} \mathrm{(Fig.} \mathrm{7).} \mathrm{Therefore,} \mathrm{the}$ microcalcifications produced by the model included sizes below the detection limit of mammography $(<0.1 \mathrm{~mm})$ and within the detection limits of mammography $(0.1-1.0 \mathrm{~mm})$ [6].

Differences in the X-ray attenuation between unlabeled and BP-Au NP labeled HA concentrations within murine MGs were also measured by micro-CT at both high $(10 \mu \mathrm{m})$ and low $(100 \mu \mathrm{m})$ resolution. Using high resolution imaging $(10 \mu \mathrm{m})$, labeling by either dose of BP-Au NPs enhanced the X-ray attenuation of all HA concentrations compared to unlabeled HA at the same HA concentration ( $p<0.05, t$-test), including at an HA concentration $(0.5 \mathrm{mg} / \mathrm{mL})$ that was otherwise undetectable by micro-CT (Fig. 6a). Using low resolution imaging $(100 \mu \mathrm{m})$, labeling by either dose of BP-Au NPs enhanced the X-ray attenuation compared to unlabeled HA at an HA concentration of $5 \mathrm{mg} / \mathrm{mL}(p<0.05, t$-test) (Fig. 6b). Note, however, that non-significant differences between unlabeled and labeled HA-Matrigel compositions at 0.5 and $25 \mathrm{mg} / \mathrm{mL}$ HA were nearly significant $(p<0.13)$, but underpowered. Post hoc power analysis indicated that these differences would become 
statistically significant if the sample size were increased from 5 to 9 specimens. The differential contrast measured for BP-Au NP labeled HA concentrations was visually apparent in grayscale micro-CT images (Fig. 7). A maximum differential contrast enhancement of 289 or $242 \mathrm{HU}$ was achieved at $25 \mathrm{mg} / \mathrm{mL}$ HA with the higher gold dose when imaging at high or low resolution, respectively (Fig. 6).

Results from the ex vivo murine tissue model showed that BP-Au NPs provided enhanced contrast at all HA concentrations (Fig. 6a), including the lowest $(0.5 \mathrm{mg} / \mathrm{mL})$ and highest $(25 \mathrm{mg} / \mathrm{mL}) \mathrm{HA}$ concentrations which were not able to be detected in the in vitro phantom (Fig. 3). Moreover, the magnitude of differential contrast obtained with the ex vivo tissue model was significantly greater than that obtained with the in vitro phantom. The greater sensitivity and contrast enhancement in the tissue model was most likely due to the lower mean background signal in the tissue model ( -300) compared to the imaging phantom ( $-14 \mathrm{HU})$.

Imaging resolution was important to investigate for clinical translation as current mammographic imaging systems have a microcalcification detection limit of $\sim 100 \mu \mathrm{m}$ [48]. Therefore, tissue samples were imaged at both high resolution $(10 \mu \mathrm{m})$ and a more clinically-relevant lower resolution $(100 \mu \mathrm{m})$. High-resolution imaging provided excellent visualization of the structure of the MGs, including the ducts which attenuated more than the adipose tissue (Fig. 7a), and detected enhanced contrast for BP-Au NP labeled HA-Matrigel compositions at each HA concentration (Fig. 6a). However, this level of resolution is not yet available clinically. At the more clinically-relevant lower resolution $(100 \mu \mathrm{m})$, the ducts were not readily visualized (Fig. 7b), but enhanced contrast was still able to be detected for BP-Au NP labeled HA-Matrigel compositions (Fig. 6b), though some differences were underpowered at the lowest and highest HA concentration, as discussed above. This is a very promising result, as future studies will continue to investigate BP-Au NPs in in vivo models using pre-clinical imaging systems with resolution lower than $10 \mu \mathrm{m}$.

All differences in X-ray attenuation between the low $(10 \mathrm{mg} / \mathrm{L})$ and high $(74 \mathrm{mg} / \mathrm{L}) \mathrm{BP}-\mathrm{Au}$ $\mathrm{NP}$ dose at the same HA concentration were not statistically significant $(p>0.23, t$-test). However, the low and high dose were chosen to be below and above, respectively, the equilibrium saturation of Au NPs bound to HA surfaces [28], which was expected to lead to differences in the surface density of BP-Au NPs labeling HA crystals and the measured Xray attenuation. Therefore, the percent of the BP-Au NP dose bound to HA and the mass of $\mathrm{BP}-\mathrm{Au} \mathrm{NPs}$ bound per HA surface area $\left(\mathrm{mg} \mathrm{Au} / \mathrm{m}^{2} \mathrm{HA}\right)$ were measured to investigate differences with HA concentration and the BP-Au NP dose. Complete binding occurred at HA concentrations $\geq 5.0 \mathrm{mg} / \mathrm{mL}$ for either BP-Au NP dose, but the percent binding was significantly lower $(p<0.001, t$-test) for the higher BP-Au NP dose at a lower HA concentration $(0.5 \mathrm{mg} / \mathrm{mL})$ where binding was incomplete (Fig. 8a). On the other hand, the surface density of BP-Au NPs was significantly greater for the higher BP-Au NP dose at each HA concentration ( $p<0.0001, t$-test) and decreased with increasing HA concentration for either BP-Au NP dose ( $p<0.0001$, ANOVA) (Fig. 8b). These differences in the surface density of BP-Au NPs were also directly confirmed by electron microscopy (not shown). Thus, a greater concentration of BP-Au NPs was able to drive equilibrium surface adsorption toward a greater surface density of BP-Au NPs labeling HA crystals surfaces, as expected [28]. However, the greater mass concentration of gold labeling HA crystals using the higher dose of BP-Au NPs (Fig. 8b) did not translate into a statistically significant increase in X-ray attenuation (Fig. 6). This suggests that while the higher BP-Au NP dose provided additional Au NPs labeling HA crystal surfaces, the additional dose was unnecessary for contrast-enhanced X-ray detection as the low BP-Au NP dose was alone sufficient to provide enhanced contrast at all HA concentrations (Fig. 6). In other words, the additional BP-Au NP dose provided negligible additional increase in contrast compared to 
the contrast between labeled and unlabeled HA concentrations. Note, however, that this result does not preclude the benefits of a higher BP-Au NP dose for in vivo delivery where only a small portion of any dose will reach the targeted tissue [26,27].

\subsection{Clinical and Scientific Implications}

Breast microcalcifications are markers for breast cancer and are one of the most common abnormalities detected by mammography during routine screening [4-7]. However, due to limitations in the sensitivity and specificity of mammography, some microcalcifications and associated breast lesions go undetected [49]. Therefore, in this study, we demonstrated that a targeted X-ray contrast agent provided enhanced contrast for the detection of microcalcifications that were otherwise undetectable with micro-CT imaging. In addition, we developed two models of breast microcalcifications, an in vitro imaging phantom and $e x$ vivo murine tissue model, to investigate the potential of BP-Au NPs as a targeted X-ray contrast agent.

To our knowledge, this is the first study demonstrating the use of surface functionalized $\mathrm{Au}$ NPs as a targeted contrast agent for breast microcalcifications. Labeling by BP-Au NPs enabled contrast-enhanced X-ray detection of HA compositions in in vitro and ex vivo models of breast microcalcifications. Contrast-enhanced detection of microcalcifications opens the possibility of improving the early detection of microcalcifications during breast cancer screening. A number of other methods are also under investigation to improve sensitivity for the detection of microcalcifications, including computer-aided detection algorithms [6,50,51], dual-energy mammography [52], computed tomography [53-55], high-resolution ultrasound [56], near-infrared fluorescence imaging with targeted molecular agents [57,58], and Raman spectroscopy $[12,59,60]$. However, a targeted X-ray contrast agent, such as BP-Au NPs, could provide a more sensitive and more readily translatable diagnostic tool that could be used in conjunction with current mammography systems.

This study also demonstrated the utility of two models of breast microcalcifications, including an in vitro imaging phantom and ex vivo murine tissue model, for evaluating targeted contrast agents. In vivo models of breast microcalcifications have been developed in mice using implanted tumor cells [44] and in rats using exogenous growth factors [45-47]. These models are more biologically-relevant and will be useful for future investigations for the targeted delivery of BP-Au NPs and radiographic imaging in vivo. However, the in vitro imaging phantom and ex vivo murine tissue model afforded more precise and a priori control over the HA concentration for an initial preclinical evaluation of a targeted contrast agent. Moreover, the methods developed to create microcalcifications in the ex vivo tissue model could be applied to an in vivo murine model.

The main limitation of this study was that HA crystals were labeled with BP-Au NPs in DI water prior to being mixed with the agarose solution or Matrigel carrier. Therefore, the mass concentration of BP-Au NPs labeling HA crystal surfaces in these models may represent a best case scenario compared to delivery in vivo. As discussed above, only a fraction of the initial BP-Au NP dose will reach the targeted site upon in vivo delivery [26,27]. Moreover, the binding of BP-Au NPs to HA crystals was previously shown to be decreased in the presence of serum proteins [28]. Therefore, the contrast enhancement achieved in this study is encouraging since the Au NP concentration was relatively low at $10-74 \mathrm{mg} / \mathrm{L}$. Previous studies on X-ray imaging have utilized Au NP concentrations ranging $0.6-2500 \mathrm{mg} / \mathrm{L}$ in vitro [22,27] and 3000-270,000 $\mathrm{mg} / \mathrm{L}$ in vivo [18-20,23-27].

Another important limitation was the small size and low background intensity of the specimens in this study relative to human breast mammography. The level of contrast enhancement, or signal-to-noise ratio, is expected to decrease with increased specimen 
thickness or density, due to increased absorption and scattering of photons by the background material or tissue. Nonetheless, this study was an important first step to demonstrate feasibility prior to ongoing studies investigating the targeted delivery of BP-Au NPs and radiographic imaging in mice in vivo, including models of radiographically dense breast tissue.

\section{Conclusions}

Contrast-enhanced detection of breast microcalcifications using BP-Au NPs was investigated using an in vitro imaging phantom and ex vivo murine tissue model comprising varying and reproducible levels of HA crystals. X-ray attenuation increased linearly with increasing HA concentration, as expected. The X-ray attenuation of HA compositions labeled by BP-Au NPs was significantly increased compared to unlabeled compositions at the same HA concentration, including an HA concentration that was otherwise undetectable by micro-CT. Contrast-enhancement was shown to be dependent on achieving a sufficient mass concentration of BP-Au NPs labeling HA crystals surfaces. Thus, BP-Au NPs enabled contrast-enhanced detection of breast microcalcifications by X-ray imaging, including at a clinically-relevant imaging resolution. BP-Au NPs may therefore have potential to improve clinical detection of breast microcalcifications by mammography.

\section{Acknowledgments}

This research was supported by the Walther Cancer Foundation and the Indiana Clinical and Translation Sciences Institute (CTSI) (NIH RR025761). The authors acknowledge the Freimann Life Science Center at the University of Notre Dame for the care of animals, the Notre Dame Integrated Imaging Facility for the use of the FE-SEM, and the Center for Environmental Science and Technology at the University of Notre Dame for the use of BET and ICPOES.

\section{References}

1. Siegel R, Naishadham D, Jemal A. Cancer statistics, 2012. CA Cancer J Clin. 2012; 62(1):10-29. [PubMed: 22237781]

2. Tabar L, Fagerberg CJ, Gad A, Baldetorp L, Holmberg LH, Gröntoft O, Ljungquist U, Lundström B, Månson JC, Eklund G. Reduction in mortality from breast cancer after mass screening with mammography. Randomised trial from the Breast Cancer Screening Working Group of the Swedish National Board of Health and Welfare. Lancet. 1985; 325(8433):829-832. [PubMed: 2858707]

3. Tabar L, Vitak B, Chen THH, Yen AMF, Cohen A, Tot T, Chiu SYH, Chen SLS, Fann JCY, Rosell J, Fohlin H, Smith RA, Duffy SW. Swedish two-county trial: Impact of mammographic screening on breast cancer mortality during three decades. Radiology. 2011; 260(3):658-663. [PubMed: 21712474]

4. Leborgne R. Diagnosis of tumors of the breast by simple roentgenography; calcifications in carcinomas. Am J Roentgenol Radium Ther. 1951; 65(1):1-11.

5. Morgan MP, Cooke MM, McCarthy GM. Microcalcifications associated with breast cancer: An epiphenomenon or biologically significant feature of selected tumors? J Mammary Gland Biol Neoplasia. 2005; 10(2):181-187. [PubMed: 16025224]

6. Cheng HD, Cai X, Chen X, Hu L, Lou X. Computer-aided detection and classification of microcalcifications in mammograms: A survey. Pattern Recogn. 2003; 36(12):2967-2991.

7. Millis RR, Davis R, Stacey AJ. The detection and significance of calcifications in the breast: A radiological and pathological study. Brit J Radiol. 1976; 49(577):12-26. [PubMed: 1276572]

8. Gulsun M, Demirkazık FB, Arıyürek M. Evaluation of breast microcalcifications according to Breast Imaging Reporting and Data System criteria and Le Gal's classification. Eur J Radiol. 2003; 47(3):227-231. [PubMed: 12927667]

9. Frappart L, Boudeulle M, Boumendil J, Lin HC, Martinon I, Palayer C, Mallet-Guy Y, Raudrant D, Bremond A, Rochet Y. Structure and composition of microcalcifications in benign and malignant 
lesions of the breast: Study by light microscopy, transmission and scanning electron microscopy, microprobe analysis, and X-ray diffraction. Hum Pathol. 1984; 15(9):880-889. [PubMed: 6469237]

10. Frappart L, Remy I, Lin HC, Bremond A, Raudrant D, Grousson B, Vauzelle JL. Different types of microcalcifications observed in breast pathology. Virchows Arch A. 1987; 410(3):179-187.

11. Busing CM, Keppler U, Menges V. Differences in microcalcification in breast tumors. Virchows Arch A. 1981; 393:307-313.

12. Haka AS, Shafer-Peltier KE, Fitzmaurice M, Crowe J, Dassari RR, Feld MS. Identifying microcalcifications in benign and malignant breast lesions by probing differences in their chemical composition using Raman spectroscopy. Cancer Res. 2002; 62:5375-5380. [PubMed: 12235010]

13. Etzioni R, Urban N, Ramsey S, McIntosh M, Schwartz S, Reid B, Radich J, Anderson G, Hartwell L. Early detection: The case for early detection. Nat Rev Cancer. 2003; 3(4):243-252. [PubMed: 12671663]

14. Smith JA. An overview of the status of imaging screening technology for breast cancer. Ann Oncol. 2004; 15(Suppl 1):i18-i26. [PubMed: 15280183]

15. Elmore JG, Barton MB, Moceri VM, Polk S, Arena PJ, Fletcher SW. Ten-year risk of false positive screening mammograms and clinical breast examinations. New Engl J Med. 1998; 338(16):1089-1096. [PubMed: 9545356]

16. Brodersen J, Siersma VD. Long-term psychosocial consequences of false-positive screening mammography. Ann Fam Med. 2013; 11(2):106-115. [PubMed: 23508596]

17. Yu S-B, Watson AD. Metal-based X-ray contrast media. Chem Rev. 1999; 99(9):2353-2378. [PubMed: 11749484]

18. Hainfeld JF. Gold nanoparticles: A new X-ray contrast agent. Brit J Radiol. 2006; 79(939):248253. [PubMed: 16498039]

19. Kim D, Park S, Lee JH, Jeong YY, Jon S. Antibiofouling polymer-coated gold nanoparticles as a contrast agent for in vivo X-ray computed tomography imaging. J Am Chem Soc. 2007; 129(24): 7661-7665. [PubMed: 17530850]

20. Cai Q-Y, Kim SH, Choi KS, Kim SY, Byun SJ, Kim KW, Park SH, Juhng SK, Yoon K-H. Colloidal gold nanoparticles as a blood-pool contrast agent for X-ray computed tomography in mice. Invest Radiol. 2007; 42(12):797-806. [PubMed: 18007151]

21. Sperling RA, Rivera Gil P, Zhang F, Zanella M, Parak WJ. Biological applications of gold nanoparticles. Chem Soc Rev. 2008; 37(9):1896-1908. [PubMed: 18762838]

22. Popovtzer R, Agrawal A, Kotov NA, Popovtzer A, Balter J, Carey TE, Kopelman R. Targeted gold nanoparticles enable molecular CT imaging of cancer. Nano Lett. 2008; 8(12):4593-4596. [PubMed: 19367807]

23. Eck W, Nicholson AI, Zentgraf H, Semmler W, Bartling S. Anti-CD4-targeted Gold nanoparticles induce specific contrast enhancement of peripheral lymph nodes in X-ray computed tomography of live mice. Nano Lett. 2010; 10(7):2318-2322. [PubMed: 20496900]

24. Reuveni T, Motiei M, Romman Z, Popovtzer A, Popovtzer R. Targeted gold nanoparticles enable molecular CT imaging of cancer: an in vivo study. Int J Nanomed. 2011; 6:2859-2864.

25. Hainfeld JF, O'Connor MJ, Dilmanian FA, Slatkin DN, Adams DJ, Smilowitz HM. Micro-CT enables microlocalisation and quantification of Her2-targeted gold nanoparticles within tumour regions. Brit J Radiol. 2011; 84(1002):526-533. [PubMed: 21081567]

26. Chanda N, Kattumuri V, Shukla R, Zambre A, Katti K, Upendran A, Kulkarni RR, Kan P, Fent GM, Casteel SW, Smith CJ, Boote E, Robertson JD, Cutler C, Lever JR, Katti KV, Kannan R. Bombesin functionalized gold nanoparticles show in vitro and in vivo cancer receptor specificity. Proc Natl Acad Sci. 2010; 107(19):8760-8765. [PubMed: 20410458]

27. Wang H, Zheng L, Peng C, Shen M, Shi X, Zhang G. Folic acid-modified dendrimer-entrapped gold nanoparticles as nanoprobes for targeted CT imaging of human lung adencarcinoma. Biomaterials. 2013; 34(2):470-480. [PubMed: 23088841]

28. Ross RD, Roeder RK. Binding affinity of surface functionalized gold nanoparticles to hydroxyapatite. J Biomed Mater Res. 2011; 99A(1):58-66.

29. Ross RD, Cole LE, Roeder RK. Relative binding affinity of carboxylate-, phosphonate-, and bisphosphonate-functionalized gold nanoparticles targeted to damaged bone tissue. J Nanopart Res. 2012; 14(10):1175. 
30. Delmas PD. Treatment of postmenopausal osteoporosis. Lancet. 2002; 359(9322):2018-2026. [PubMed: 12076571]

31. Uludag H, Kousinioris N, Gao T, Kantoci D. Bisphosphonate conjugation to proteins as a means to impart bone affinity. Biotechnol Prog. 2000; 16(2):258-267. [PubMed: 10753453]

32. Baker R, Rogers KD, Shepherd N, Stone N. New relationships between breast microcalcifications and cancer. Brit J Cancer. 2010; 103(7):1034-1039. [PubMed: 20842116]

33. Turkevich J, Stevenson PC, Hillier J. A study of the nucleation and growth processes in the synthesis of colloidal gold. Discuss Faraday Soc. 1951; 11:55-75.

34. Roeder RK, Converse GL, Leng H, Yue W. Kinetic effects on hydroxyapatite whiskers synthesized by the chelate decomposition method. J Am Ceram Soc. 2006; 89(7):2096-2104.

35. Du S, Kendall K, Toloueinia P, Mehrabadi Y, Gupta G, Newton J. Aggregation and adhesion of gold nanoparticles in phosphate buffered saline. J Nanopart Res. 2012; 14:758.

36. Boone JM, Nelson TR, Lindfors KK, Seibert JA. Dedicated breast CT: Radiation dose and image quality evaluation. Radiology. 2001; 221(3):657-667. [PubMed: 11719660]

37. Buist DS, Porter PL, Lehman C, Taplin SH, White E. Factors contributing to mammography failure in women aged 40-49 years. J Natl Cancer Inst. 2004; 96(19):1432-1440. [PubMed: 15467032]

38. Jackson VP, Hendrick RE, Feig SA, Kopans DB. Imaging of the radiographically dense breast. Radiology. 1993; 188(2):297-301. [PubMed: 8327668]

39. Kolb TM, Lichy J, Newhouse JH. Comparison of the performance of screening mammography, physical examination, and breast US and evaluation of factors that influence them: An analysis of 27,825 patient evaluations. Radiology. 2002; 225(1):165-175. [PubMed: 12355001]

40. Boyd NF, Guo H, Martin LJ, Sun L, Stone J, Fishell E, Jong RA, Hislop G, Chiarelli A, Minkin S. Mammographic density and the risk and detection of breast cancer. New Engl J Med. 2007; 356(3):227-236. [PubMed: 17229950]

41. Fondrinier E, Lorimier G, Guerin-Boblet V, Bertrand A-F, Mayras C, Dauver N. Breast microcalcifications: Multivariate analysis of radiological and clinical factors for carcinoma. World J Surg. 2002; 26(3):290-296. [PubMed: 11865363]

42. Cox RF, Morgan MP. Microcalcifications in breast cancer: Lessons from physiological mineralization. Bone. 2013; 52(2):437-450. [PubMed: 23334083]

43. Vargo-Gogola T, Rosen JM. Modelling breast cancer: One size does not fit all. Nat Rev Cancer. 2007; 7(9):659-672. [PubMed: 17721431]

44. Cox RF, Hernandez-Santana A, Ramdass S, McMahon G, Harmey JH, Morgan MP. Microcalcifications in breast cancer: novel insights into the molecular mechanism and functional consequence of mammary mineralisation. Brit J Cancer. 2012; 106(3):525-537. [PubMed: 22233923]

45. Liu F, Misra P, Lunsford EP, Vannah JT, Liu Y, Lenkinski RE, Frangioni JV. A dose- and timecontrollable syngeneic animal model of breast cancer microcalcification. Breast Cancer Res Treat. 2010; 122(1):87-94. [PubMed: 19760034]

46. Liu F, Bloch N, Bhushan KR, de Grand AM, Tanaka E, Solazzo S, Mertyna PM, Goldberg N, Frangioni JV, Lenkinski RE. Humoral BMP-2 is sufficient for inducing breast cancer microcalcification. Mol Imaging. 2008; 7(4):175-186. [PubMed: 19123988]

47. Inoue K, Liu F, Hoppin J, Lunsford EP, Lackas C, Lenkinski RE, Fujii H, Frangioni JV. Highresolution computed tomography of single breast cancer microcalcifications in vivo. Mol Imaging. 2011; 10(4):295-304. [PubMed: 21504703]

48. Swamy R. Histological correlation of mammographically detected breast calcifications: A need for rational protocols. Diagn Histopathol. 2009; 15(12):582-588.

49. Smith RA, Duffy SW, Tabar L. Breast cancer screening: The evolving evidence. Oncology. 2012; 26(5):471-486. [PubMed: 22730603]

50. Freer TW, Ulissey MJ. Screening mammography with computer-aided detection: Prospective study of 12,860 patients in a community breast center. Radiology. 2001; 220(3):781-786. [PubMed: 11526282]

51. Chan H-P, Doi K, Vybrony CJ, Schmidt RA, Metz CE, Lam KL, Ogura T, Wu Y, Macmahon H. Improvement in radiologists' detection of clustered microcalcifications on mammograms: The 
potential of computer-aided diagnosis. Invest Radiol. 1990; 25(10):1102-1110. [PubMed: 2079409]

52. Lemacks MR, Kappadath SC, Shaw CC, Liu X, Whitman GJ. A dual-energy subtraction technique for microcalcification imaging in digital mammography: A signal-to-noise analysis. Med Phys. 2002; 29(8):1739-1751. [PubMed: 12201421]

53. Prionas ND, Lindfors KK, Ray S, Huang SY, Beckett LA, Monsky WL, Boone JM. Contrastenhanced dedicated breast CT: Initial clinical experience. Radiology. 2010; 256(3):714-723. [PubMed: 20720067]

54. Gong X, Vedula AA, Glick SJ. Microcalcification detection using cone-beam CT mammography with a flat-panel imager. Phys Med Biol. 2004; 49(11):2183-2195. [PubMed: 15248571]

55. Lai C-J, Shaw CC, Chen L, Altunbas MC, Liu X, Han T, Wang T, Yang WT, Whitman GJ, Tu S-J. Visibility of microcalcification in cone beam breast CT: Effects of X-ray tube voltage and radiation dose. Med Phys. 2007; 34(7):2995-3004. [PubMed: 17822008]

56. Yang W, Suen M, Ahuja A, Metreweli C. In vivo demonstration of microcalcification in breast cancer using high resolution ultrasound. Brit J Radiol. 1997; 70:685-690. [PubMed: 9245879]

57. Zaheer A, Lenkinski RE, Mahmood A, Jones AG, Cantley LC, Frangioni JV. In vivo near-infrared fluorescence imaging of osteoblastic activity. Nat Biotechnol. 2001; 19:1148-1154. [PubMed: 11731784]

58. Lenkinski RE, Ahmed M, Zaheer A, Frangioni JV, Goldberg SN. Near-infrared fluorescence imaging of microcalcification in an animal model of breast cancer. Acad Radiol. 2003; 10(10): 1159-1164. [PubMed: 14587634]

59. Stone N, Baker R, Rogers K, Parker AW, Matousek P. Subsurface probing of calcifications with spatially offset Raman spectroscopy (SORS): Future possibilities for the diagnosis of breast cancer. Analyst. 2007; 132(9):899-905. [PubMed: 17710265]

60. Baker R, Matousek P, Ronayne KL, Parker AW, Rogers K, Stone N. Depth profiling of calcifications in breast tissue using picosecond Kerr-gated Raman spectroscopy. Analyst. 2006; 132(1):48-53. [PubMed: 17180179] 
a
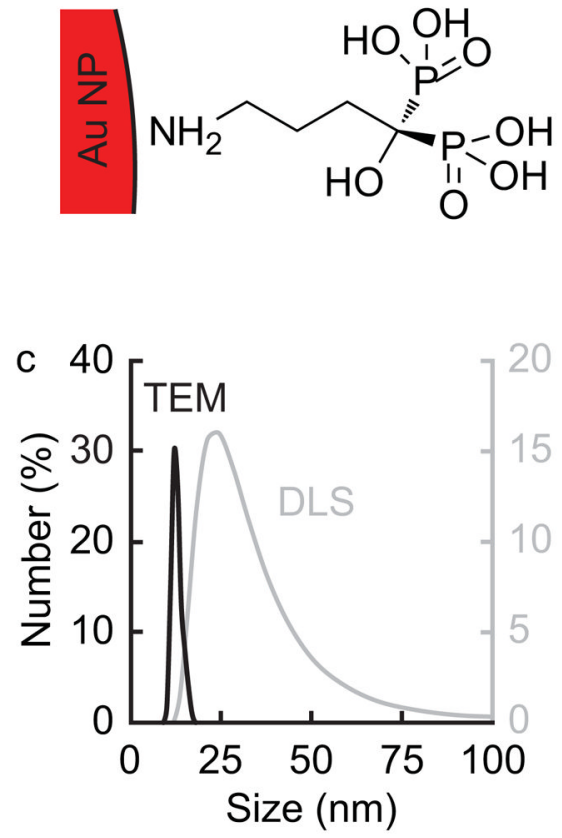

b

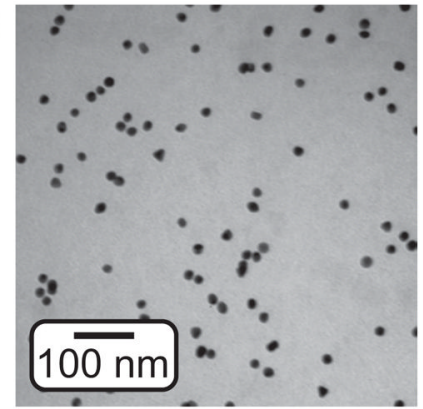

d

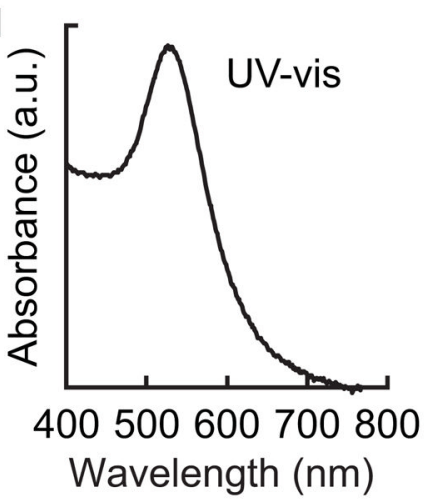

Fig. 1.

(a) Gold nanoparticles were surface functionalized with alendronate, a bisphosphonate with a primary amine for binding to gold surfaces opposite phosphonate groups for targeting calcium ions on HA crystal surfaces. (b) Representative TEM micrograph showing spherical and monodispersed BP-Au NPs. (c) The particle diameter distribution measured by TEM and the hydrodynamic diameter distribution measured by DLS. The mean ( \pm standard deviation) physical particle diameter and hydrodynamic diameter were 12.8 (1.6) $\mathrm{nm}$ and 45.8 (1.5) $\mathrm{nm}$, respectively. (d) UV-vis spectra of BP-Au NPs showing the surface plasmon resonance peak at $\sim 527 \mathrm{~nm}$. 


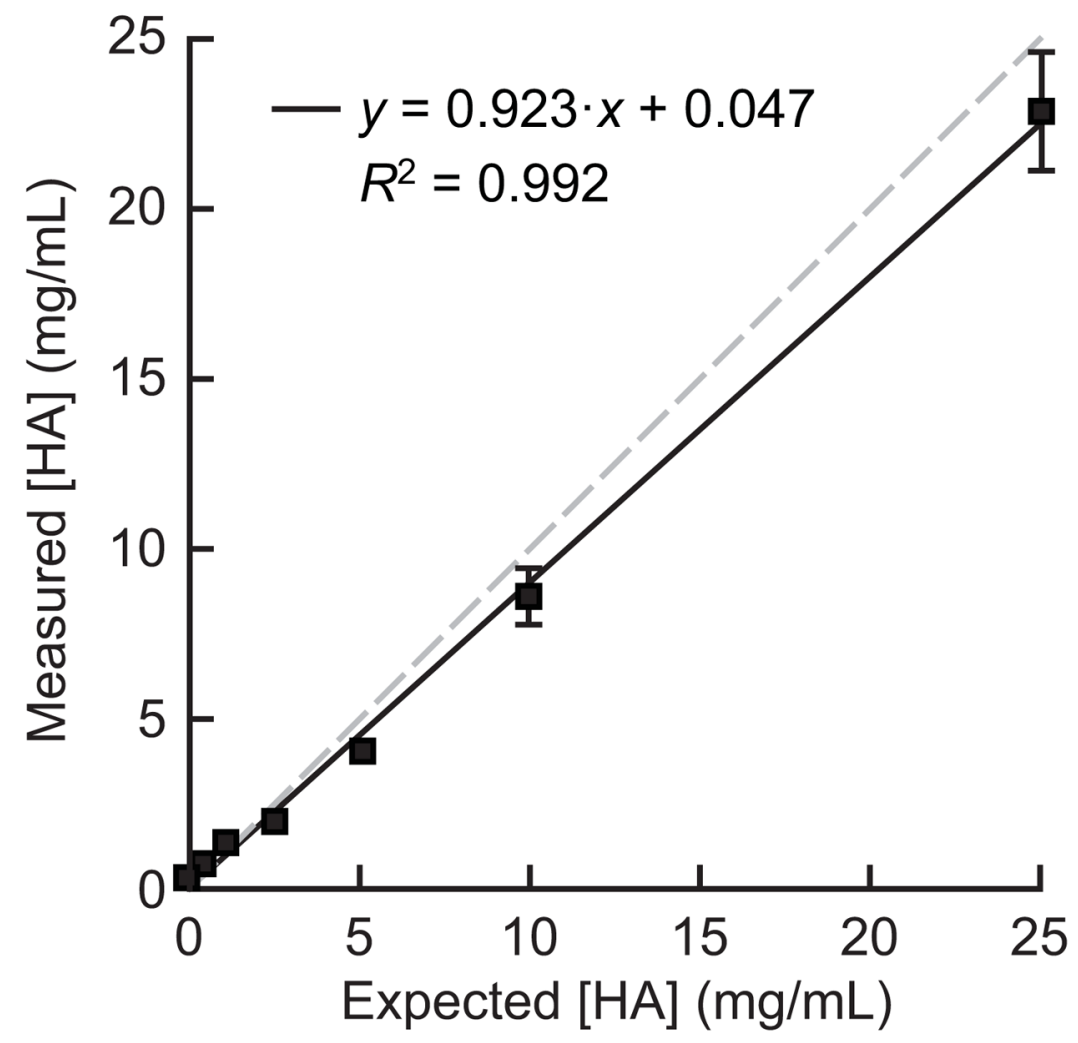

Fig. 2.

The expected HA concentration $(\mathrm{mg} / \mathrm{mL})$ within $10 \mu \mathrm{L}$ HA-agarose pellets of the in vitro imaging phantom was validated against the measured HA concentration $(\mathrm{mg} / \mathrm{mL})$ from ICPOES. Error bars show one standard deviation of the mean $(n=3$ /group) and error bars not shown lie within the data point. The dashed gray line shows a one-to-one equivalence. Differences between expected and measured HA concentrations were significantly different ( $p<0.05$, paired $t$-test), but the mean error was $-8.3 \%$, indicating reasonable accuracy. More importantly, linear least squares regression indicated that HA concentrations were highly reproducible $\left(R^{2}=0.992\right)$. 


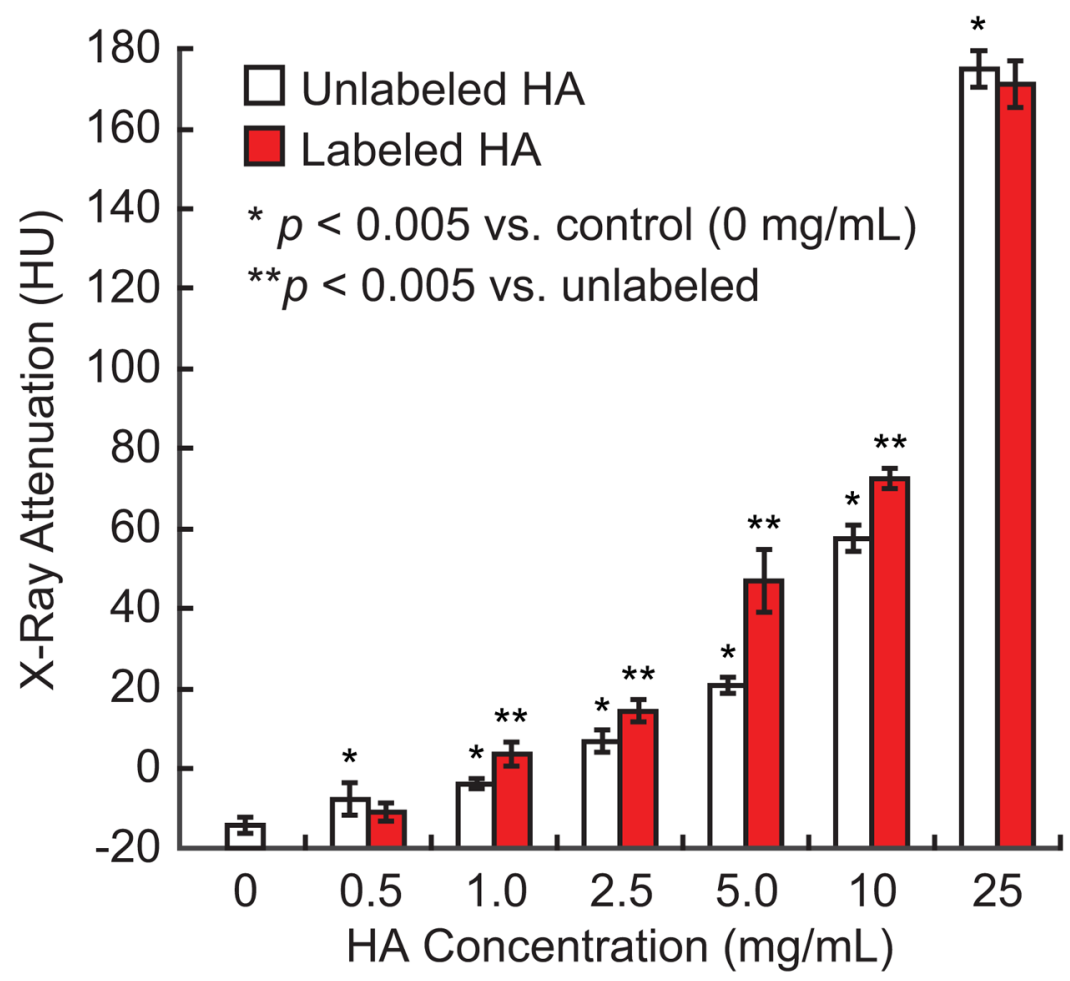

Fig. 3.

The X-ray attenuation (HU) measured by micro-CT for the in vitro imaging phantom comprising unlabeled and BP-Au NP labeled HA crystals at varying HA concentrations within an agarose hydrogel. Error bars show one standard deviation of the mean $(n=5 /$ group). X-ray attenuation increased with increasing HA concentration for both labeled and unlabeled HA-agarose pellets ( $p<0.001$, ANOVA). All unlabeled HA concentrations exhibited significantly greater X-ray attenuation compared to the $0 \mathrm{mg} / \mathrm{mL}$ agarose control $\left({ }^{*} p<0.005, t\right.$-test). BP-Au NPs enhanced the X-ray attenuation of HA concentrations ranging from $1-10 \mathrm{mg} / \mathrm{mL}$ compared to unlabeled $\mathrm{HA}$ at the same concentration $(* * p<$ $0.005, t$-test). 


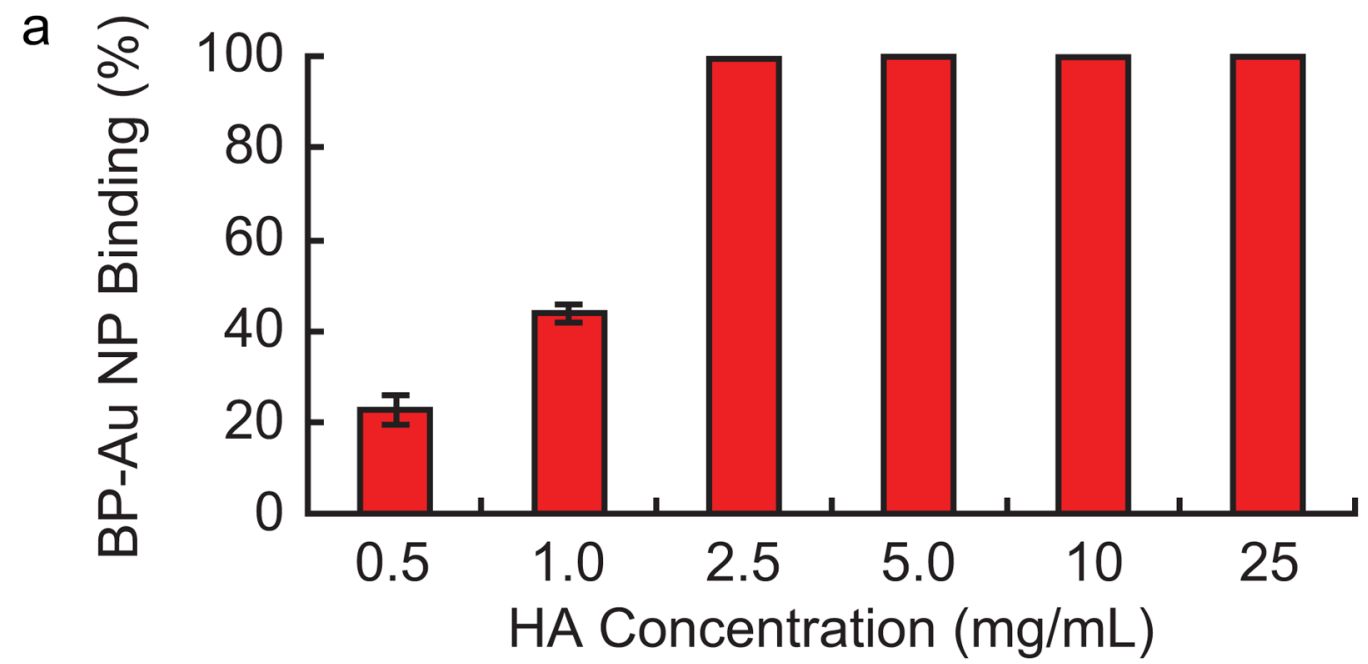

b

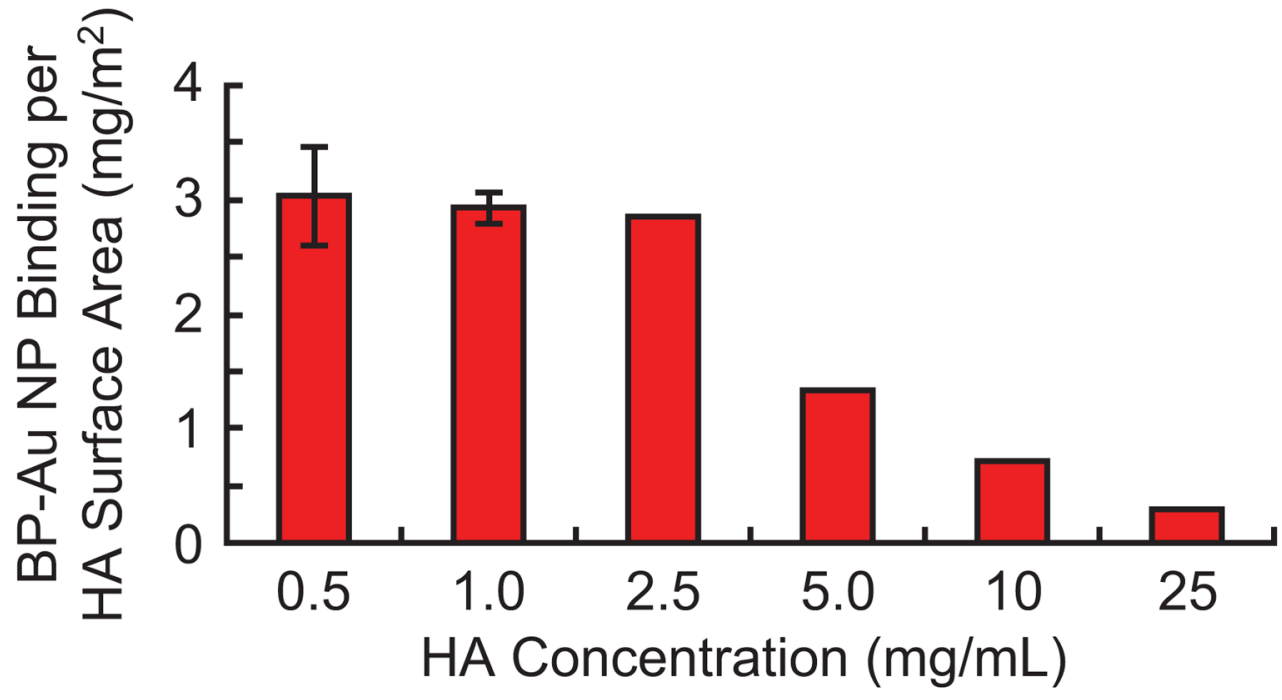

Fig. 4.

$\mathrm{BP}-\mathrm{Au}$ NP binding to varying concentrations of HA crystals in HA-agarose pellets was characterized by measuring the concentration of unbound BP-Au NPs using ICP-OES. (a) The percent of BP-Au NPs bound to HA crystals showed complete binding of the BP-Au NP dose at HA concentrations $\geq 2.5 \mathrm{mg} / \mathrm{mL}$ and decreased percent binding with decreasing HA concentration ( $p<0.0001$, ANOVA). (b) The mass of BP-Au NPs bound per HA surface area (mg Au/m $\mathrm{m}^{2} \mathrm{HA}$ ) showed that HA crystals surfaces were saturated with BP-Au NPs at HA concentrations $\leq 2.5 \mathrm{mg} / \mathrm{mL}$ and the surface density decreased with increasing HA concentration $(p<0.0001$, ANOVA). Error bars show one standard deviation of the mean $(n$ $=3$ ) and error bars not shown were negligibly small. 


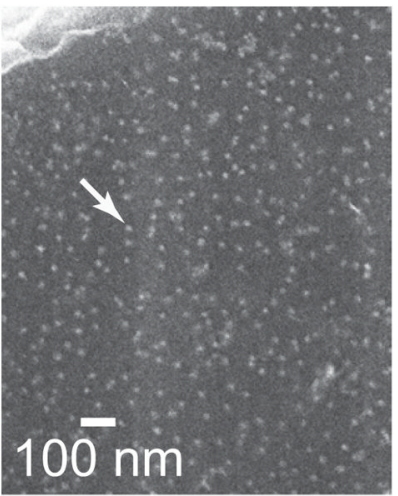

$0.5 \mathrm{mg} / \mathrm{mL}$

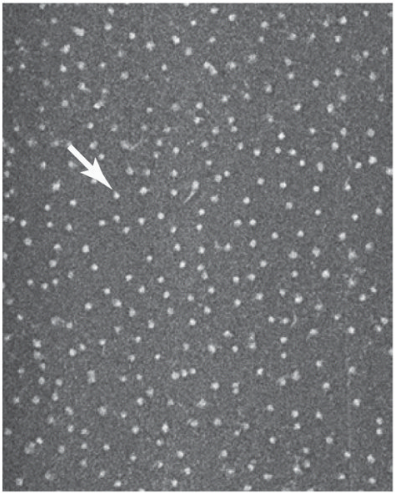

$5.0 \mathrm{mg} / \mathrm{mL}$

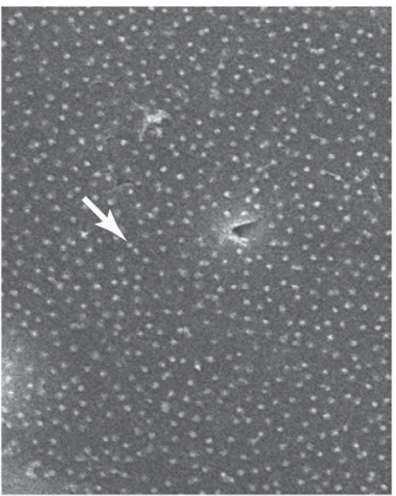

$1.0 \mathrm{mg} / \mathrm{mL}$

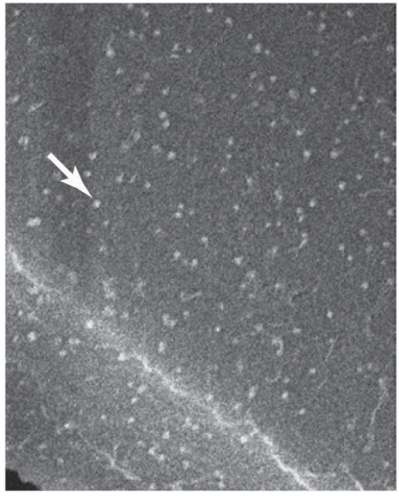

$10 \mathrm{mg} / \mathrm{mL}$

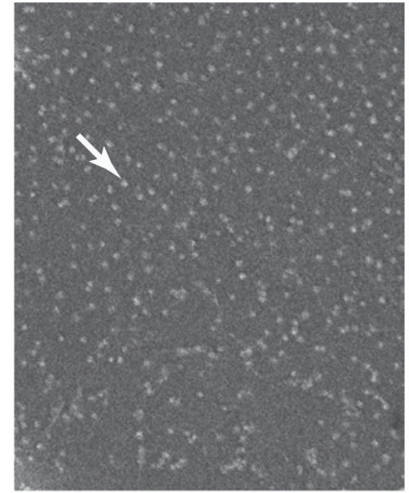

$2.5 \mathrm{mg} / \mathrm{mL}$

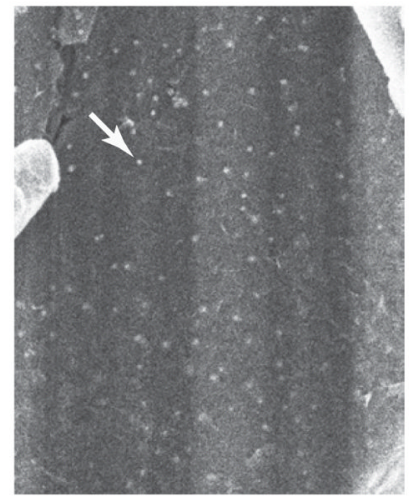

$25 \mathrm{mg} / \mathrm{mL}$

Fig. 5.

Representative FE-SEM micrographs showing the surface density of BP-Au NPs (arrows) on HA crystal surfaces. The surface density appeared to increase with decreasing HA concentration and became saturated at HA concentrations $\leq 2.5 \mathrm{mg} / \mathrm{mL}$, in agreement with quantitative measurements of the mass of BP-Au NPs bound per HA surface area (Fig. 4b). 

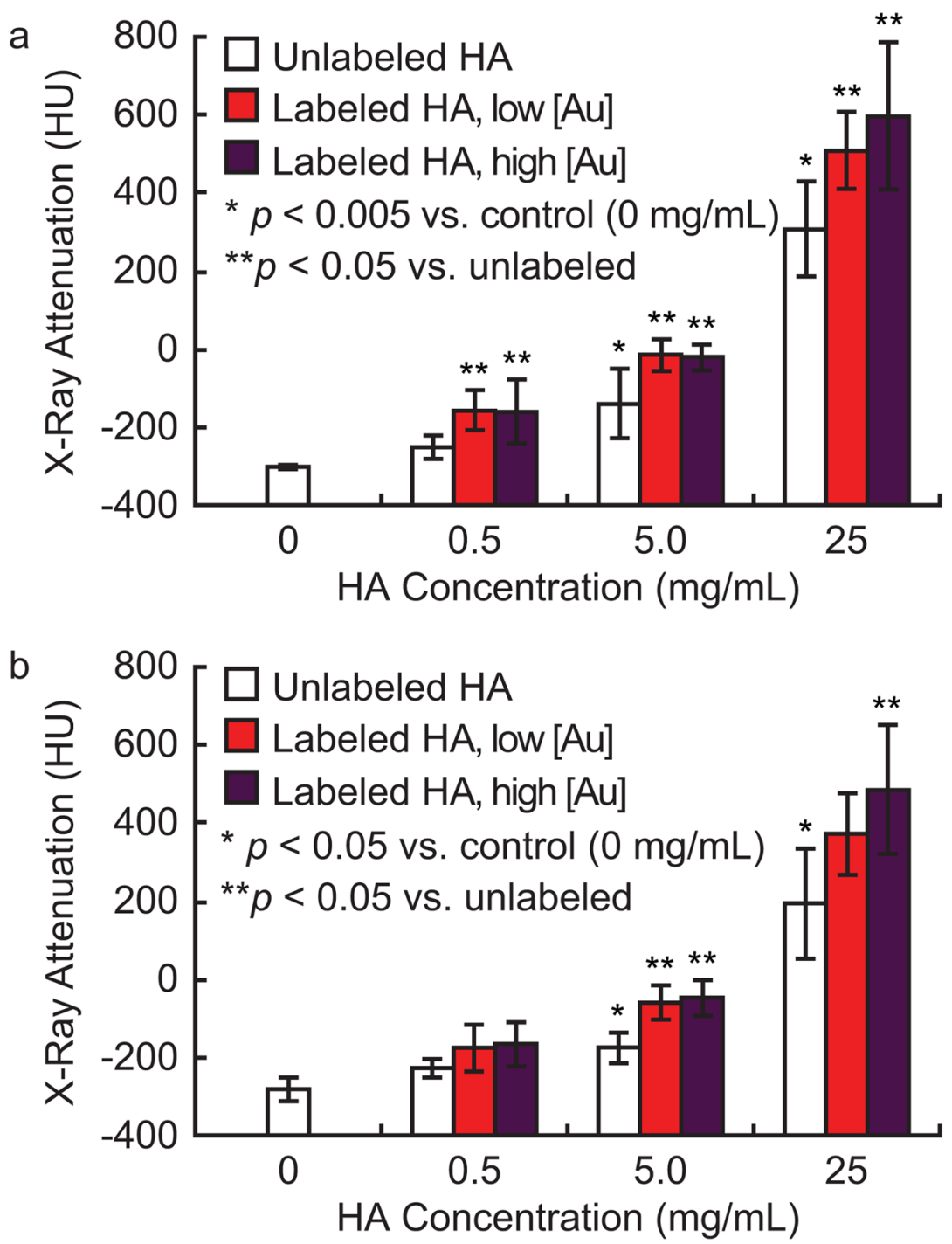

Fig. 6.

The X-ray attenuation (HU) measured by micro-CT for the ex vivo tissue model comprising unlabeled and BP-Au NP labeled HA crystals at varying HA concentrations within HAMatrigel compositions injected into murine MGs and imaged at (a) high $(10 \mu \mathrm{m})$ and (b) low $(100 \mu \mathrm{m})$ resolution. Error bars show one standard deviation of the mean $(n=5)$. X-ray attenuation increased with increasing HA concentration for both labeled and unlabeled HAMatrigel compositions imaged at both high and low resolution ( $p<0.0001$, ANOVA). (a) Using high resolution imaging $(10 \mu \mathrm{m})$, BP-Au NPs enhanced the X-ray attenuation of HAMatrigel compositions at all HA concentrations $(* * p<0.05$ labeled vs. unlabeled, $t$-test), including at levels that were otherwise undetectable by micro-CT $(* p<0.005$ vs. control 0 $\mathrm{mg} / \mathrm{mL}$, t-test). (b) Using low imaging resolution, BP-Au NPs enhanced the X-ray attenuation of HA-Matrigel compositions at HA concentrations $\geq 5.0 \mathrm{mg} / \mathrm{mL}$ compared to unlabeled HA at the same concentration (**p $<0.05$ labeled vs. unlabeled, $t$-test). All differences in X-ray attenuation between the low $(10 \mathrm{mg} / \mathrm{L})$ and high $(74 \mathrm{mg} / \mathrm{L})$ BP-Au NP dose at the same HA concentration were not statistically significant ( $p>0.23, t$-test). 
a
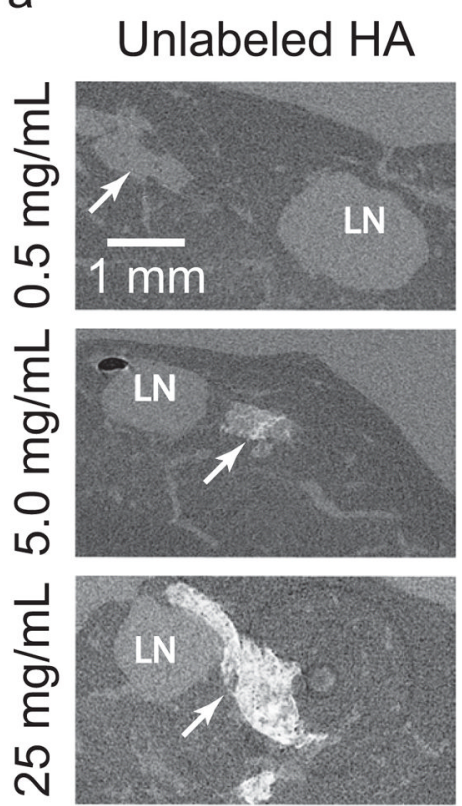

b
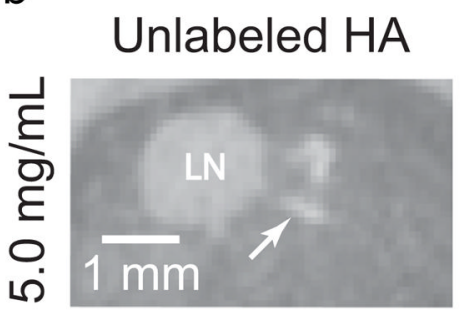

Labeled HA, low [Au]
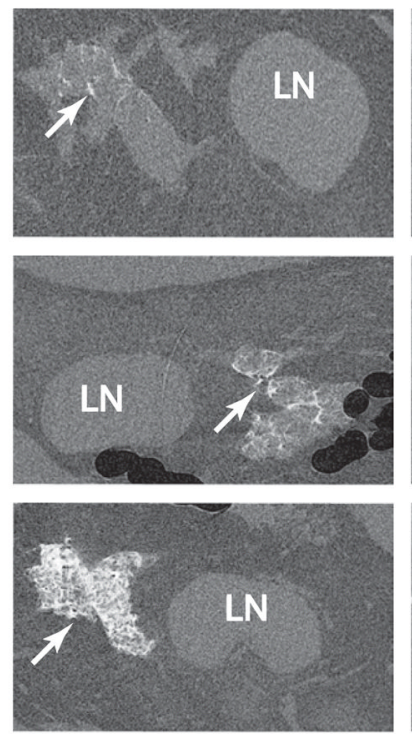

Labeled HA, low [Au]

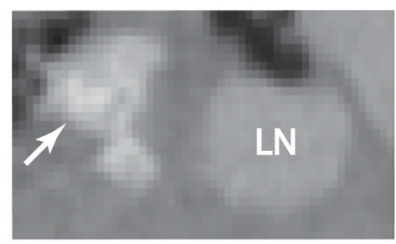

Labeled HA, high [Au]
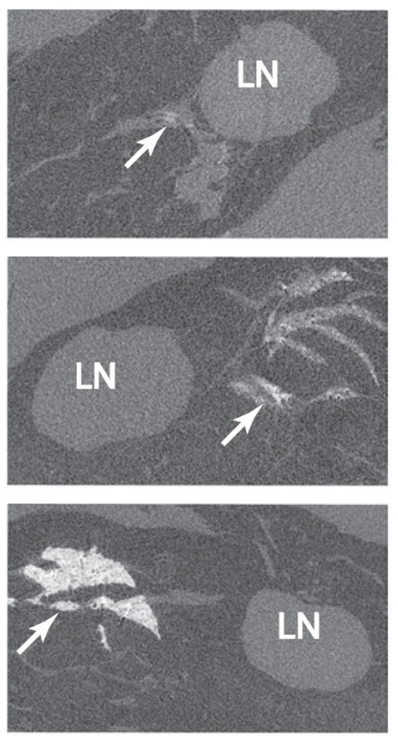

Labeled HA, high [Au]

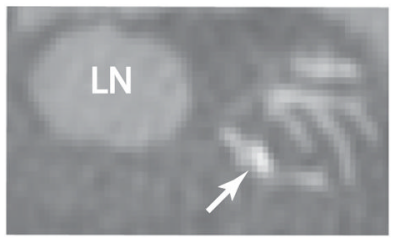

Fig. 7.

Representative grayscale micro-CT images taken at high $(10 \mu \mathrm{m})$ and (b) low $(100 \mu \mathrm{m})$ resolution, showing unlabeled and BP-Au NP labeled (arrows) HA-Matrigel compositions within excised murine MGs. Enhanced contrast was visually apparent for BP-Au NP labeled HA compared to unlabeled HA at HA concentrations of $0.5 \mathrm{mg} / \mathrm{mL}$ and $5 \mathrm{mg} / \mathrm{mL}$ at high resolution and $5 \mathrm{mg} / \mathrm{mL} \mathrm{HA}$ at low resolution. The lymph node (LN) was used as an anatomical landmark for injections. 

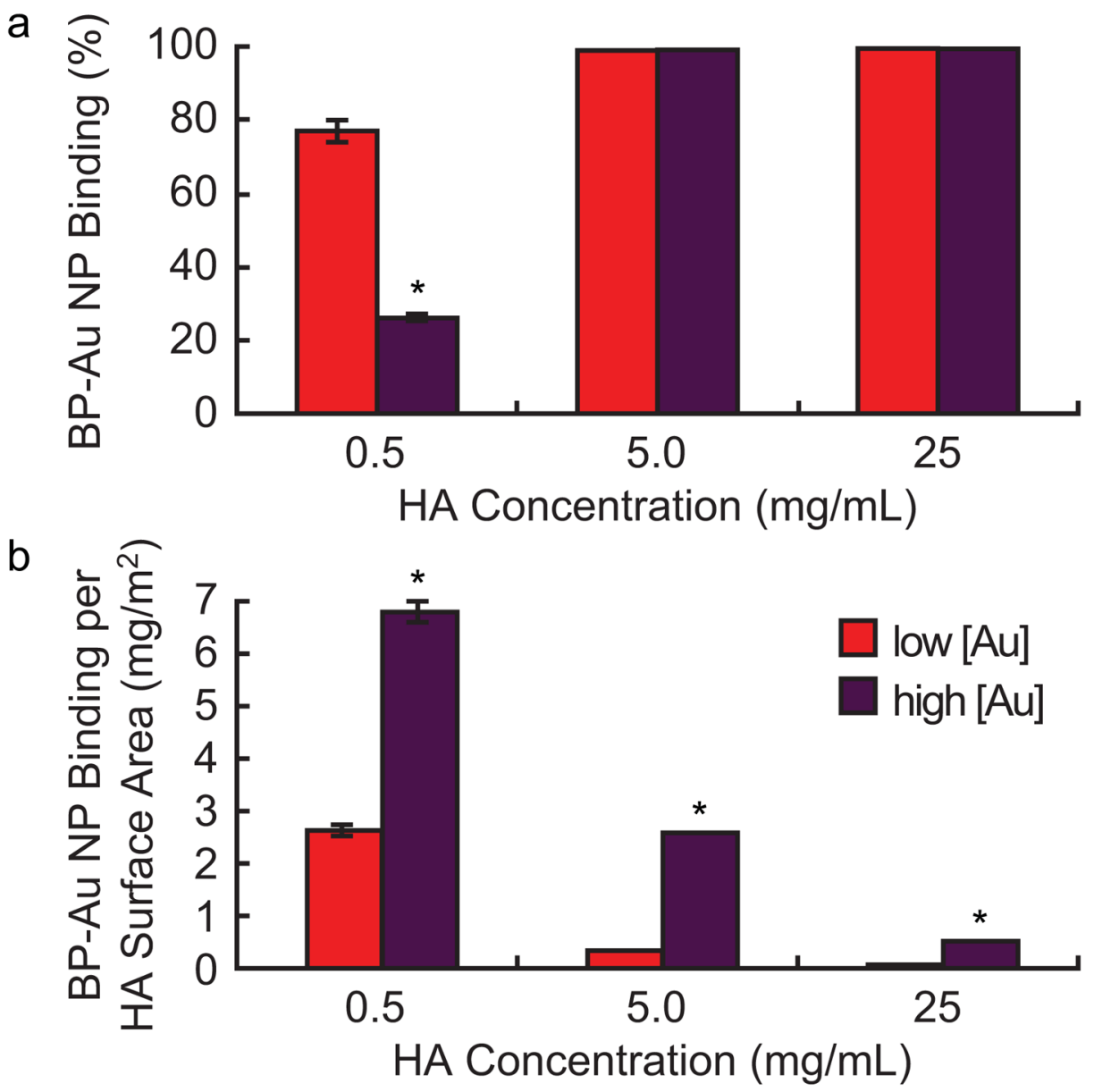

Fig. 8.

BP-Au NP binding to varying concentrations of HA crystals in HA-Matrigel compositions was characterized by measuring the concentration of unbound BP-Au NPs using ICP-OES. (a) Complete binding occurred at HA concentrations $\geq 5.0 \mathrm{mg} / \mathrm{mL}$ for either BP-Au NP dose, but the percent binding was significantly lower $\left({ }^{*} p<0.001, t\right.$-test) for the higher BP$\mathrm{Au}$ NP dose when binding was incomplete at a lower HA concentration $(0.5 \mathrm{mg} / \mathrm{mL})$. (b) The mass of BP-Au NPs bound per HA surface area (mg Au/ $\mathrm{m}^{2} \mathrm{HA}$ ) showed that the surface density of BP-Au NPs was significantly greater for the higher BP-Au NP at each HA concentration $(* p<0.0001, t$-test $)$ and decreased with increasing HA concentration for either BP-Au NP dose ( $p<0.0001$, ANOVA). Error bars show one standard deviation of the mean $(n=3)$ and error bars not shown were negligibly small. 